\title{
Emergent Properties of Odor Information Coding in a Representational Model of the Salamander Olfactory Bulb
}

\author{
Joel White, ${ }^{1}$ Kathryn A. Hamilton, ${ }^{2}$ Samuel R. Neff, ${ }^{1}$ and John S. Kauer ${ }^{1}$ \\ 'Section of Neuroscience, Department of Neurosurgery, and Department of Cell Biology and Anatomy, Tufts Medical \\ School and New England Medical Center, Boston, Massachusetts 02111 and ${ }^{2}$ Department of Cellular Biology and \\ Anatomy, Louisiana State University Medical Center, Shreveport, Louisiana 71130
}

In the salamander olfactory bulb, mitral output cells exhibit a variety of responses to electrical and odor stimulation, but the cellular interactions within the bulb that give rise to these responses are not completely understood. We have developed a computer model to investigate whether available data are sufficient for formulating a simulated bulb circuit that can generate realistic mitral cell output. A set of coupled difference equations incorporating mathematical descriptions of anatomical and physiological data was used to calculate changes in membrane potentials of olfactory bulb neurons over time. Model mitral cells showed responses to simple orthodromic and antidromic electrical stimuli that were similar to salamander intracellular responses. Without changing the parameters of the equations, simulated odor stimuli were applied that elicited complex patterns of mitral depolarization, spike activation, and hyperpolarization that emerged from the interactions among the numerous elements in the model. As with the electrical stimuli, model mitral responses to odor were also strikingly similar to those of real mitral cells. As an initial test of how different circuit components contribute to the responses, the lateral interactions between mitral cells and bulbar interneurons were manipulated. Tests with reduced lateral interactions and other tests with no inhibitory synaptic connections both produced mitral cell outputs that were uncharacteristic of salamander recordings. The similarity of the model's output to the complex properties of salamander single-cell recordings suggests that several critical features of the bulb circuit responsible for shaping mitral cell responsivity have been captured. In addition, the experiments in which parameters were manipulated suggest that the cellular interactions included in the model play an important role in producing the complexities of mitral cell responses observed in the salamander.

Realistic mathematical models of systems as complex as the brain require the simultaneous solution of thousands of equations with many interacting variables. Models in neuroscience range from those describing "microscopic" events such as cur-

\footnotetext{
Recived June 17, 1991; revised Oct. 15, 1991; accepted Dec. 11, 1991.

We thank W. Dent for photography and G. Vidaver for assistance in programming earlier versions of the model. This work was supported by grants from USPHS, ONR, Pew Freedom Trust, and the Department of Neurosurgery.

Correspondence should be addressed to Dr. Joel White (Box 178), Department of Neurosurgery, New England Medical Center, 750 Washington Street, Boston, MA 02111.

Copyright $c 1992$ Society for Neuroscience $0270-6474 / 92 / 121772-09 \$ 05.00 / 0$
}

rents in axonal or dendritic membranes (Hodgkin and Huxley, 1952; Rall, 1964), to those describing "macroscopic" events in single cells or entire neuronal circuits (Rall and Shepherd, 1968; Meredith, 1986b; Schild, 1986, 1988; Freeman, 1987; Gelperin ct al., 1989; Li and Hopfield, 1989; Wilson and Bower, 1989). One feature common to many of these simulations is that complex physiological phenomena are modeled by interactions among many simpler processes. In a similar way, interactions among many neuronal elements appear to underlie odor information processing in the olfactory system. A model based on explicit, completely defined elements that replicates both single cell and ensemble responses might therefore assist in elucidating how distributed events functionally interact to encode olfactory stimuli (Rall and Shepherd, 1968; Haberly and Bower, 1989; Wilson and Bower, 1989; Kauer, 1991).

Physiological studies of the olfactory bulb have concentrated on single-unit recordings of bulbar output neurons and their responses to electrical and odor stimulation. For the following discussion, we use the term "mitral cells" to refer to both mitral and tufted output cells (for physiological differences between mitral and tufted cells in mammals, see Scott, 1981). Mitral cells exhibit relatively simple responses to electrical stimulation, but firing patterns in response to precisely controlled odor stimuli are generally more complex (Kauer, 1974; Kauer and Moulton, 1974; Mair, 1982; Meredith, 1986a; Harrison and Scott, 1986; Hamilton and Kauer, 1988, 1989; Wellis et al., 1989). The responses of a single mitral cell can be different for different odors and for different concentrations of the same odor. At the same time, different odors can elicit similar responses in different cells, indicating that firing patterns per se do not encode odor quality information (Kauer, 1974; Meredith, 1986a). Thus, it is generally thought that it is the temporal patterns of activity distributed across many mitral cells that encode odor quality information (for review, sce Kauer, 1991). To understand how such patterns are generated and how they encode highly specific odorant information, one needs to understand the interactions among bulbar cells. At the present time, we have little specific information on the dynamic, distributed properties of these interactions. Most of the information available is static (e.g., anatomical) or inferred from single-cell recordings. The information that has accumulated, however, has prompted us to investigate whether a model network based on available bulbar cell data could produce physiologically realistic single mitral cell responses.

To investigate the distributed processing properties of the olfactory system, we have developed a computer model based on the olfactory bulb of the tiger salamander (Ambystoma $t i$ - 
grinum). The advantage of using the salamander system for these purposes is that a relatively large amount of information has already been gathered in this one species on the anatomy of the olfactory mucosa and bulb (Herrick, 1924; Graziadei and Graziadei, 1976; Kauer, 1980; Breipohl et al., 1982; MackaySim et al., 1982), on single unit receptor and bulbar physiology (Kauer, 1974; Kauer and Moulton, 1974; Kauer and Shepherd, 1977; Getchell and Shepherd, 1978a,b; Trotier and MacLeod, 1983; Hamilton and Kauer, 1988, 1989; Firestein and Werblin, 1989), on global response properties of the epithelium and bulb using 2-deoxyglucose and voltage-sensitive dyes (Lancet et al., 1982; Orbach and Cohen, 1983; Kauer et al., 1987; Kauer, 1988; Kent and Mozell, 1988; Senseman et al., 1990), and on olfactory-guided behavior (Mason et al., 1980). Our approach has been to describe mathematically as many of these anatomical and physiological data as are available, and then to calculate explicit membrane potentials in large numbers of single bulbar cells using standard integration procedures similar to those used by others (Hodgkin and Huxley, 1952; Rall, 1964; Rall and Shepherd, 1968; Schild, 1986, 1988; Freeman, 1987; Li and Hopfield, 1989; Wilson and Bower, 1989). Although this model is specific to the salamander olfactory bulb, the approach we have used should be applicable to any neural system for which there are sufficient anatomical and physiological data.

\section{Materials and Methods}

Consistent with the general anatomy of the mammalian olfactory bulb (Halasz, 1990), the salamander bulb contains mitral cells (output cells; abbreviated in the model as MIT; Fig. $1 A$ ), the glomerular compartments of mitral cells (GLM), periglomerular cells (interneurons; PGL), and granule cells (interneurons; GRL) (Herrick, 1924). In addition, epithelial receptor cells (abbreviated as REC) have been included. The numbers and connections of the cellular elements are shown schematically in Figure $1 \mathrm{~A}$. Other types of intrabulbar cells, centrifugal connections from higher levels, and recurrent mitral axon collaterals are not yet included.

The program for the model is written in " $\mathrm{C}$ " and runs on an IBMcompatible 80486-based PC and i860-based math coprocessor (Microway, Inc.). This hardware combination provides high-speed calculation, enabling interactive experimentation, at relatively low cost. Each iteration (about $1.25 \times 10^{\circ}$ floating point arithmetic operations) requires approximately $100 \mathrm{msec}$ of calculation time. A 3000 iteration run (representing $4.5 \mathrm{sec}$ of real time) takes approximately $300 \mathrm{sec}$. Thousands of cells (7248) and connections $(119,760)$ are represented (Fig. 1A), but many aspects of the circuit have been simplified. The model has been flexibly designed to accommodate greater numbers of cells and parameters as additional data are obtained. The number of each cell type (Fig. $I A)$ is about 1000-fold less than the actual numbers in the salamander; however, the ratios of the numbers of cells to one another are accurate for this species (J. S. Kauer, unpublished observations; see Halasz, 1990, for review of mammalian values). The number of receptor cells is about one-half the appropriate value, so the strengths of their synaptic inputs to bulbar elements have been doubled.

The membrane potential of each cell is represented as a value in a numerical array. At each time point, the membrane potential of a neuronal element is based on its previous potential, plus the sum of all synaptic inputs onto it, modified by passive membrane decay coefficients. These influences on membrane potential are calculated by a set of coupled difference equations. As an example of the calculations carried out for all of the cellular elements, the following simplified equation represents those used for PGL cells:

$$
\begin{aligned}
& E_{\mathrm{PGl}}^{\prime}[\mathrm{pgl \#}]=E_{\mathrm{POL}}[\mathrm{pgl} \#] \\
& +\left[\sum _ { \text { rec } \# - 0 } ^ { N _ { \text { REC } } } \left(E_{\text {REC }}[\text { rec \#] }] \cdot \operatorname{conn}[\text { rec\#] })\right.\right. \\
& \left.+\sum_{\operatorname{sim} m=-0}^{N_{G L M}}\left(E_{G L M}[\operatorname{glm} \#] \cdot \operatorname{conn}[\operatorname{glm} \#]\right)-\text { decay }\right] \cdot d t \text {. }
\end{aligned}
$$

A
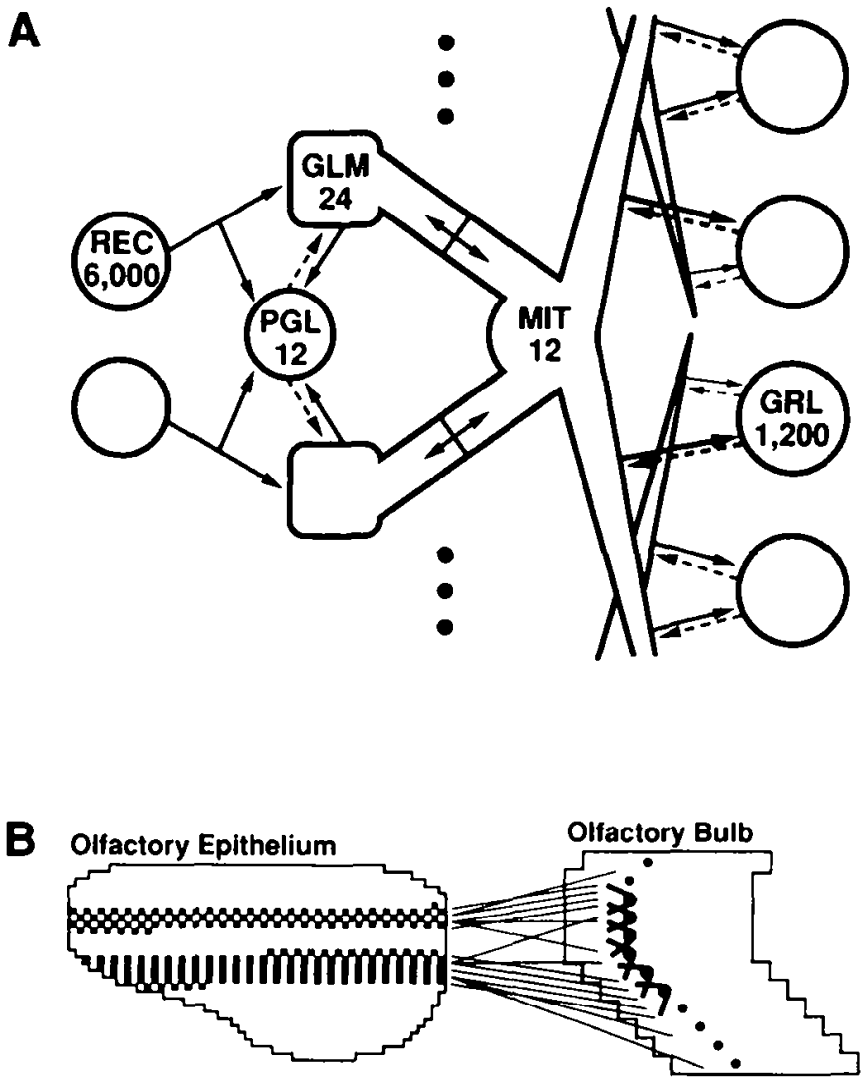

Figure 1. A, Simplified block diagram illustrating the interconnections of elements in the modeled olfactory bulb. The number in each block is the number of elements of that type. Arrows represent connections between cellular elements: solid arrows, excitatory synapses; broken arrows, inhibitory synapses; double-headed arrows, electrotonic connections. $R E C$, receptor cell; $G L M$. glomerular tuft of mitral cell; $P G L$, periglomerular cell; $M I T$, soma of mitral and secondary dendrites; $G R L$, granule cell. Vertical ellipses indicate replication of each element to the full size of the model. Thickness of $M I T \% G R L$ arrows indicates relative strengths of these connections along dendrites of one MIT (see Materials and Methods). $B$. Schematic illustration of the connections between the olfactory epithelium and the olfactory bulb in the model, similar to a dorsal view of the salamander head. Left is rostral; the midline is at the top. Solid circles in the olfactory bulb represent the positions of MIT somata spread evenly across the width of the bulb (MITs 0-11). MITs 2-7 are the slightly larger circles shown with primary dendrites; these are the MITs showing the responses illustrated in Figure 4. Blocks on the epithelium indicate regions of the most activated receptor cells and correspond to the regions shown in the insets to Figure 4. Lines joining these regions to the bulb indicate schematically the degree of direct and divergent connections between the epithelium and the bulb.

In this example, each PGL cell receives inputs from both receptor and glomerular units. $E_{\text {PGi. }}^{\prime}[$ pgl\#] = present membrane potential for each PGL; $E_{\mathrm{PGL}}[\mathrm{pgl} \#]=\mathrm{PGL}$ membrane potential from the previous iteration; "conn" = synaptic connection between cells (e.g., conn[rec\#] = the weighted synaptic connection from each receptor cell to the periglomerular cell being evaluated); "decay" = the influence of the passive membrane time constant on charge injected into the PGL cell. At each time iteration, the membrane potential of every cell in the model is determined using standard forward Euler integration (i.e., multiplication by $d t$; see, e.g., Wilson and Bower, 1989). Since this technique is least accurate when membrane potentials change rapidly, an adaptive timestep size algorithm was used to reduce the time step when a cell exhibited a voltage change greater than $5 \mathrm{mV}$ per iteration. The maximum time step permitted per iteration represents a real time of $1.5 \mathrm{msec}$.

Synaptic connections ("conn" in above equation) are represented either as "spike only" (such as axodendritic synapses between receptor and periglomerular cells and between receptor and mitral cells), or as 
"spike and graded" (such as dendrodendritic synapses and those at all other locations). A "spike only" synapse produces a change in postsynaptic conductance only if a spike has occurred in the presynaptic element. A "spike and graded" synapse elicits a change in postsynaptic conductance in response to both a presynaptic spike and graded changes in presynaptic membrane potential. The presynaptic threshold for graded synaptic release was $-50 \mathrm{mV}$. The conductance change elicited by a presynaptic spike for both synpase types is described by

$$
g(t)=\frac{t \cdot e^{-t / \tau}}{G_{\max }}
$$

where $G_{\max }=\tau \cdot e^{-1}$ (Rall and Shepherd, 1968; Wilson and Bower, 1989). For an excitatory synapse, $\tau=10 \mathrm{msec}$; for an inhibitory synapse, $\tau=$ $150 \mathrm{msec}$. The resting membrane potential of all modeled cells was -70 $\mathrm{mV}$, the excitatory reversal potential was $0 \mathrm{mV}$, and the inhibitory reversal potential was $-95 \mathrm{mV}$.

These time courses and reversal potentials are not intended to depict specific subtypes of synaptic conductances, since many synaptic interactions in the olfactory bulb are still not precisely defined. For example, evidence indicates that the granule-to-mitral inhibitory interaction is mediated by a bicuculline-sensitive chloride conductance (Nowycky et al., 1981; Jahr and Nicoll, 1982), suggesting a GABA mechanism. Although physiological details of $\mathrm{GABA}_{\mathrm{A}}$ synpases in other systems are well described, studies show that the olfactory bulb also contains a number of other possible inhibitory mechanisms (Halasz, 1990). Since details of the synaptic conductance at each of these synapses in the salamander olfactory bulb are unknown, the values used in the model therefore represent "generic" conductances. The inhibitory conductance has a slow time course and reversal potential below the resting potential, and the excitatory conductance has a fast time course and a reversal potential well above the resting potential. As more data on specific synaptic conductances for each cell type become available, they will be included in the model (e.g., see Wellis and Kauer, 1991).

The polarities of the synapses between the various cells are shown in Figure $1 A$ (solid arrows indicate excitatory connections; broken arrows indicate inhibitory connections). The strengths of the connections are best estimates based on physiological and morphological observations from the salamander and other vertebrates. Granule cells are generally agreed to be inhibitory (Shepherd, 1972). The nature of periglomerular to mitral (glomerular) synapses, however, is still debated (Martinez and Freeman, 1984; Mori et al., 1984), and it is possible that they are a heterogeneous population. In the present model, we have designated all periglomerular cells to be inhibitory onto mitral cells. The degree of divergence and convergence between cells derives from published anatomical observations. As shown schematically in Figure $1 B$, each 500 contiguous receptor cells project to one-half of the GLMs and PGLs, with the majority of the receptors in a region projecting to a restricted area of the bulb and fewer receptors projecting to other bulbar areas (Kauer, 1980, 1991). The pattern of connectivity between modeled elements in the bulb circuit is summarized in line A of Table 1 ("Normal") and is based on salamander anatomical data (Herrick, 1924). The strength of synaptic connections between MITs and GRLs and between GLMs and PGLs decreases logarithmically over distance as an approximation of voltage decay along a dendritic cable. The synaptic connection between a mitral cell and a granule cell anatomically close to the mitral soma has a greater effect on mitral membrane potential (thick arrows in Fig. $1 A$ ) than connections between that mitral cell and granule cells farther from the mitral cell body (thin arrows in Fig. $1 A$ ).

Each mitral cell is modeled with three compartments (the soma/ secondary dendrites and two glomerular units). Separate calculations are made for inputs into these two distinct regions of the cell, enabling each mitral cell to have at least two glomerular tufts as has been described for the salamander by Herrick (1924). The electrotonic connections between the GLMs and the MITs are calculated using cable equations (Rall, 1964), with rate constants derived from turtle anatomical data (Mori et al., 1981). Each receptor, periglomerular, and granule cell is modeled as a single compartment. Glomeruli are implicitly included in the model to the degree that there is convergence of the large population of receptor cells onto smaller populations of PGLs and GLMs, and interactions between these cells take place over limited distances. Thus, effective glomeruli are generated for the glomerular compartments in each mitral cell and their associated periglomerular cells. Any more explicit parcellation of functional interactions (glomeruli) between receptor cells and bulbar cells would be artificial because the structural and/or functional properties upon which glomerular segregation are based are not yet defined. This is, however, one of the many aspects of bulbar function that the model allows us to explore in detail.

Action potentials are elicited when the membrane potential reaches spike threshold. Instead of performing individual, computer time-consuming Hodgkin-Huxley calculations at each spike occurrence, spikes are recorded as a state variable for each cell and spike effects on postsynaptic cells are calculated at the synapses. Thus, the effects of each spike on membrane potential are included without recalculating the full shape of the action potential at each occurrence, since we assume each action potential in a given cell to have the same effect. For display, a spike waveform appropriate for salamander neurons is calculated once (see Rall and Shcpherd, 1968, for a description of the algorithm) and added at the appropriate points after membrane calculations are completed. Because this is not a fully compartmental model, we have not calculated changes in membrane potential over the time course of Hodgkin-Huxley events, nor have we yet examined the effects of making explicit Hodgkin-Huxley calculations at each spike occurrence. At this stage of development, we are interested in the activity of each cell in terms of action potential firing patterns and relatively slow synaptic events. With expansion into multiple compartments, Hodgkin-Huxley calculations will probably be necessary.

For simulated orthodromic electrical stimuli, the spike state variable (see above) is set simultaneously in a subpopulation of receptor cells. For antidromic stimuli, the variable is set in a subpopulation of mitral cells. All elements have active membrane and generate spikes except for the GLMs, which support only passive membrane potential changes. "Spontaneous" activity is determined by a random number generator constrained by the average firing frequency for each cell type: receptor cells, 0.33 spikes/sec (Getchell and Shepherd, 1978a,b; Trotier and MacLeod, 1983); mitral cells, 0.5 spikes/sec (Kauer and Shepherd, 1977); periglomerular cells, 0.1 spikes/sec (estimated); granule cells, 0.1 spikes/ sec (estimated).

Simulated odor stimulation (1 sec duration) was applied nonuniformly to the receptor population with two regions of distributed high activity and lower activity across the remainder of the mucosa (see Figs. $1 B ; 4$, insets). Receptors defined as having higher sensitivity to the odor stimulus were made to depolarize and fire action potentials during the stimulus with frequencies proportional to the stimulus intensity. With low-intensity stimulation, receptors were depolarized for $1 \mathrm{sec}$; with high-intensity stimulation, receptors werc depolarized for $2 \mathrm{sec}$ to replicate the longer effective influence of higher-intensity odor stimuli seen in physiological experiments. The receptors were depolarized with a slow rise at stimulus onset $(300 \mathrm{msec})$ and a slower fall at stimulus cessation (low-intensity stimuli had decay times of $1500 \mathrm{msec}$; highintensity, $3000 \mathrm{msec}$ ). These response properties are based on data from extracellular and intracellular recordings from salamander olfactory receptor cells (Getchell and Shepherd, 1978a,b; Trotier and MacLeod, 1983; Firestein and Werblin, 1989). Although simplified, the essential properties of this patterned activation of the epithelial sheet are consistent with electrophysiological (Kauer and Moulton, 1974; MackaySim and Kubie, 1981) and voltage-sensitive dye (Kent and Mozell, 1988) observations.

\section{Results}

Using reasonable physiological values based on experimental data, the model is stable and produces membrane potentials and spiking behavior in each of the cell types that are strikingly similar to intracellular recordings. Figure 2 is a comparison of model and salamander mitral responses after electrical stimulation, Figure 4 is a comparison of the responses after odor stimulation, and Figure 3 shows examples of interneuron (PGL and GRL) responses.

Low-intensity orthodromic stimulation [single synchronous spikes triggered in 142 clustered receptor cells (not shown)] caused depolarization in glomerular and periglomerular elements. $\mathrm{Mi}$ tral cells then depolarized, eliciting spikes with latencies of 30$34 \mathrm{msec}$ in the middle four (of 12) mitral cells (responses of two cells are shown in Fig. $2 \mathrm{Aa}$ ), followed by hyperpolarization primarily due to granule cell input. Modeled mitral cell responses compare well with intracellular recordings from salamander mi- 


\section{A Low Intensity Orthodromic}

a. Model

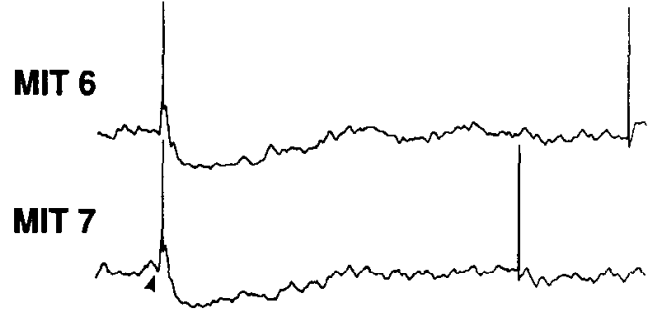

b. Salamander

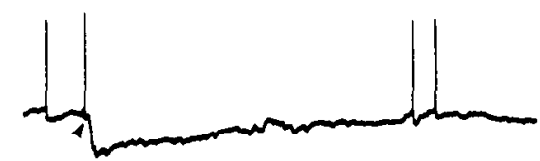

C Antidromic

a. Model

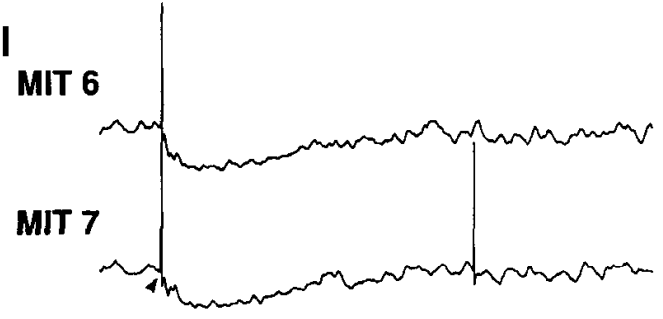

\section{b. Salamander}

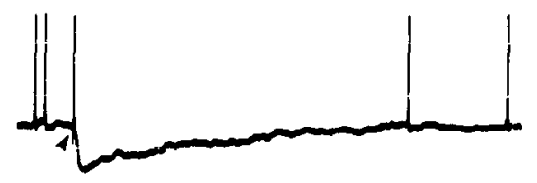

\section{B High Intensity Orthodromic}

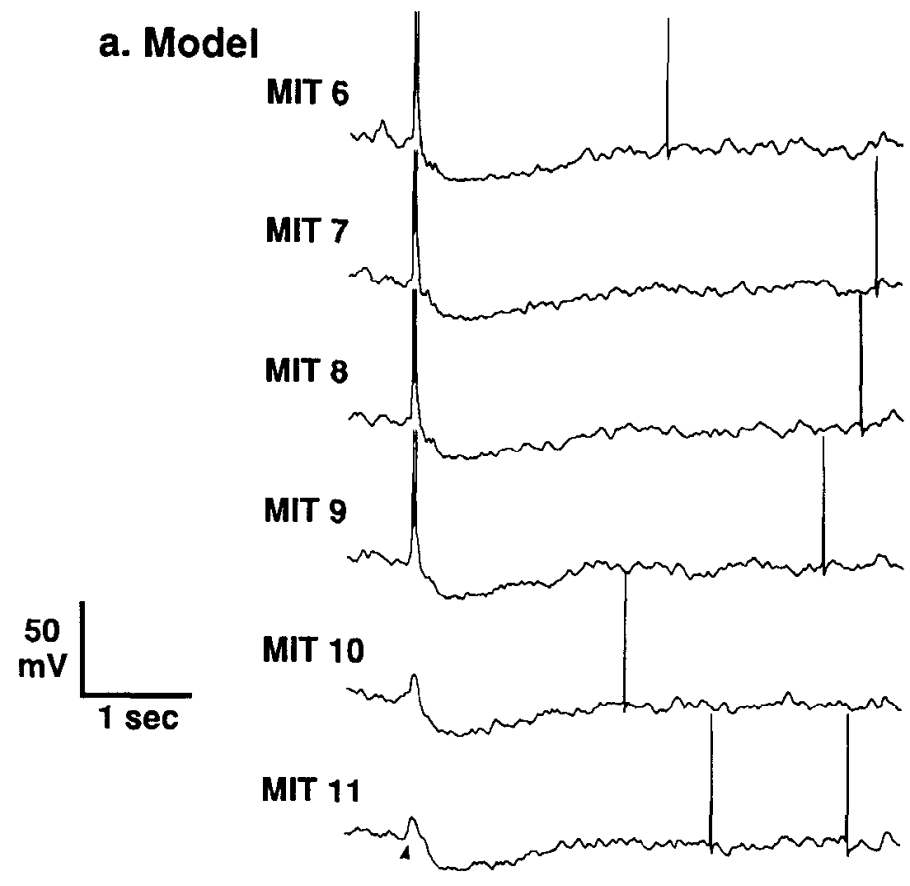

b. Salamander

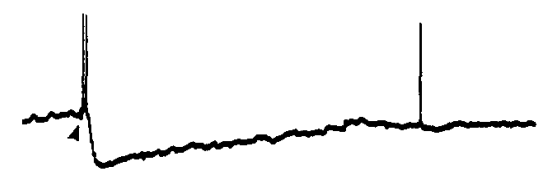

Figure 2. Examples of modeled and real mitral cell responses to simulated low $(A)$ and high $(B)$ intensity orthodromic and antidromic $(C)$ electrical stimulation. Upper traces $(A a, B a, C a)$ in each panel illustrate modeled output; lower traces $(A b, B b, C b)$ show actual intracellular recordings from the salamander (see Hamilton and Kauer, 1988, for methods). Orthodromic responses $(A b$ and $B b)$ are from the same cell. Onset of electrical stimuli is indicated by arrowheads. Note the similarities between the model outputs and the actual recordings with regard to the depolarizing and hyperpolarizing events (see Results). Stimulus intensities for salamander records: $A b, 0.3 \mathrm{~mA} ; B b, 0.5 \mathrm{~mA} ; C b, 1 \mathrm{~mA}$.

tral cells. A typical example is shown in Figure $2 A b$ : here the salamander mitral cell fired a single action potential $(18 \mathrm{msec}$ latency), followed by a period of hyperpolarization.

Examples of PGL and GRL responses for this stimulus are shown in Figure 3, $A a$ and $A b$, respectively. Converging inputs to the PGL caused the membranc potential to depolarize rclative to resting potential, and the cell fired action potentials at a rate higher than the random, "spontaneous" rate, even in the absence of stimulation (right side of Fig. 3Aa). Upon stimulation (arrowhead), the cell exhibited a large depolarization, lasting about $200 \mathrm{msec}$, that produced a burst of action potentials. In the absence of stimuli, the GRL membrane potential remained close to the resting potential, and the cell fired action potentials only in response to the simulated electric shock (Fig. $3 A b$ ). The stimulus elicited a small depolarization, lasting about $270 \mathrm{msec}$, that produced a burst of two action potentials.

With higher-intensity orthodromic stimulation (single synchronous spikes triggered in 428 clustered receptor cells, including those stimulated at low intensity), the sequences of events in the model cells were similar to those at low intensity. However, more cells responded, showing larger depolarizations and hyperpolarizations, and a second mitral response pattern emerged (responses of six cells are shown in Fig. $2 \mathrm{Ba}$ ). The middle eight mitral cells each fired two action potentials, and depolarizations without spikes were seen in the cells flanking those that fired (e.g., MIT 10 and 11 in Fig. $2 \mathrm{Ba}$ ). Thus, more mitral cells were triggered to fire than with low-intensity stimulation, and spike latencies were shorter (22-30 msec for MITs 2-9). After the depolarization with or without spikes, all mitral cells exhibited a long hyperpolarization resulting primarily from granule cell input.

As shown in Figure $2 B b$ (for the same cell as in Fig. $2 A b$ ), salamander mitral cells respond to higher-intensity orthodromic stimulation with shorter spike latencies (15 msec in this cell), a maximum of two or three spikes, and a larger and longer-duration hyperpolarization (Hamilton and Kauer, 1988). These response properties are reliably produced by model mitral cells (compare traces in Fig. $2 B a, B b$ ). The slight difference in the 


\section{A Low Intensity Orthodromic}

a.

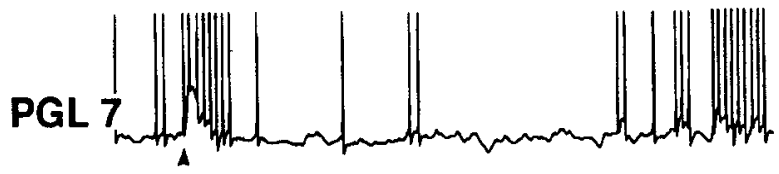

b.

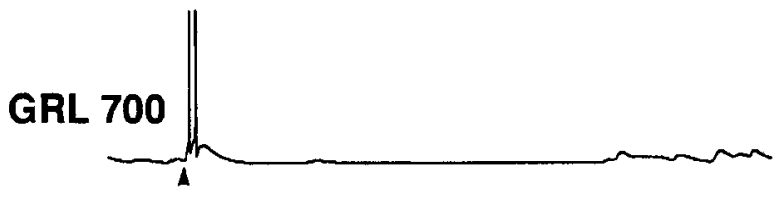

B Low Intensity Odor

a.

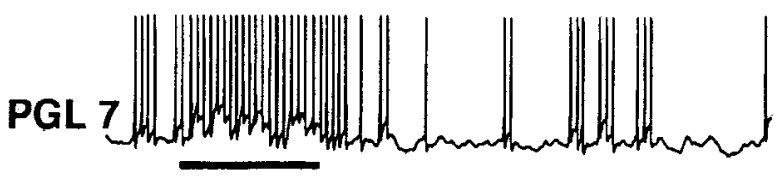

b.

GRL 700

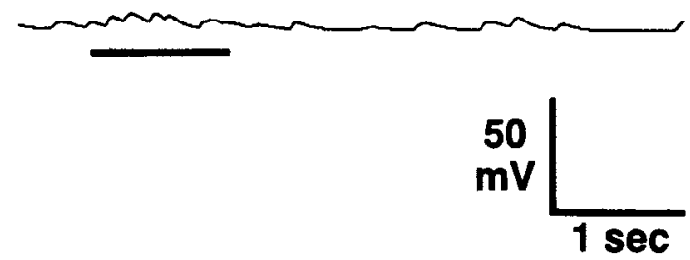

Figure 3. Examples of model interneuron responses to low-intensity orthodromic $(A)$ stimulation, as in Figure $2 A a$, and low-intensity odor $(B)$ stimulation, as in Figure 4Aa. These interncurons are directly connected to MIT 7. PGLs tended to be noisy ( $A a$ and $B a$ ) and responded to electrical stimulation (arrowhead in $A a$ ) with a large depolarization and burst of action potentials. With simulated odor stimulation (horizontal bar in $B a$ ), the PGL fired a longer burst of action potentials. GRLs exhibited fewer action potentials $(A b$ and $B b)$ and responded to electrical stimulation (arrowhead in $A b$ ) with a small depolarization and brief burst of action potentials. With odor stimulation (horizontal bar in $B b$ ), the GRL depolarized slightly but did not reach spike threshold.

time course of the hyperpolarizing response between the model and the salamander recording may be due to inaccuracies in the estimate of the inhibitory synaptic conductance duration or lack of centrifugal input from higher brain levels.

To simulate antidromic stimulation, the middle six of the 12 mitral cells were driven directly to fire synchronous action potentials. The spikes arose from the baseline with no preceding depolarization (unlike orthodromic stimulation) and were followed by a period of hyperpolarization (responses of two cells are shown in Fig. $2 \mathrm{Ca}$ ). As with orthodromic stimulation, the shapes of the spike onset and the hyperpolarization in the modeled cells were similar to those seen in salamander mitral cells (Fig. 2Cb).

After determining the model's responses to simulated electrical stimuli, we investigated how the model responded to simulated odor stimuli. Tests with "odor" stimuli were made with out changing the parameters of the model circuitry from those
Table 1. Connections between elements in the olfactory bulb model

\begin{tabular}{lllll} 
Condition & $\begin{array}{lll}\text { GLM: } \\
\text { PGL }\end{array}$ & $\begin{array}{l}\text { PGL: } \\
\text { GLM }\end{array}$ & $\begin{array}{l}\text { MIT: } \\
\text { GRL }\end{array}$ & $\begin{array}{l}\text { GRL: } \\
\text { MIT }\end{array}$ \\
\hline A. Normal & $1: 7$ & $1: 15$ & $1: 960$ & $1: 7$ \\
B. Reduced (1/5) & $1: 1$ & $1: 3$ & $1: 192$ & $1: 1$ \\
C. No lateral & $1: 1$ & $1: 2$ & $1: 100$ & $1: 1$ \\
\hline
\end{tabular}

The values indicate the number of elements connected reciprocally.

used for electrical stimulation. In the salamander, there is good evidence that odors applied to the olfactory epithelium elicit spatial activity patterns distributed nonuniformly across the mucosa (Kauer and Moulton, 1974; Mackay-Sim and Kubie, 1981; Kent and Mozell, 1988). Experiments with the model indicate that a variety of mitral cell responses can be elicited by activating the reccptor cells in such a spatially and temporally distributed way. Similar response variety has been seen in vertebrate mitral cells (Kauer, 1974; Kauer and Moulton, 1974; Mair, 1982; Meredith, 1986a; Harrison and Scott, 1986; Hamilton and Kauer, 1989; Wellis et al., 1989), and the response types can be roughly grouped into overlapping categories. In general, cells exhibit spike firing patterns, based on early responsive events to odor stimulation, that have been termed excitatory (E-type), suppressive (S-type), or no response ( $\mathrm{N}$ type), with a number of subtypes for the $E$ - and S-type categories (Kauer, 1974). Model mitral cell spike responses also tend to fall into these categories, so the E-S-N nomenclature will be used here as a descriptive tool for comparison. Since our goal was not to induce the model to replicate the odor response of any one cell, but rather to assess the extent to which the model naturally gave rise to outputs that were similar to those seen in the animal, model parameters such as connectivity and synaptic properties were not manipulated. The response patterns observed arose solely from the pattern and mode of receptor stimulation.

A simulated low-intensity odor stimulus elicited a range of relatively simple responses in mitral cells (Fig. $4 A a$ ). For example, MIT 7 showed an excitatory response and fired more or less continuously for the duration of the stimulus application. This spike firing pattern is reminiscent of $E_{1}$-type responses (sustained excitation). MIT 3 fired one driven spike near the beginning of the stimulus, and other cells did not reach spike threshold ( $\mathrm{N}$-like responses; the other spikes during the stimulus in Fig. $4 \mathrm{~A} a$ are spontaneous). These membrane potential changes and spiking patterns of the model responses are similar to those seen in salamander mitral cells after low-intensity odor stimulation (Kauer, 1974; Hamilton and Kauer, 1989). As an example, Figure $4 A b$ shows the response of a recorded mitral cell to a 1 sec pulse of cineole $\left(5 \times 10^{-3}\right.$ saturated vapor). The excitatory response of this salamander cell is qualitatively similar to the output of MIT 7.

Examples of PGL and GRL responses for this odor stimulus are shown in Figure 3, $B a$ and $B b$, respectively. During the stimulus, the PGL depolarized above threshold and fired a long burst of action potentials outlasting the duration of the stimulus. The GRL exhibited a small depolarization during the stimulus, but no action potentials.

Unlike for electrical stimulation, a simulated higher-intensity odor stimulus did not result in simple increases in the number of model mitral cell spikes (Fig. $4 B a$ ). Instead, MITs 2, 3, and 


\section{A Low Intensity Odor}

a. Model

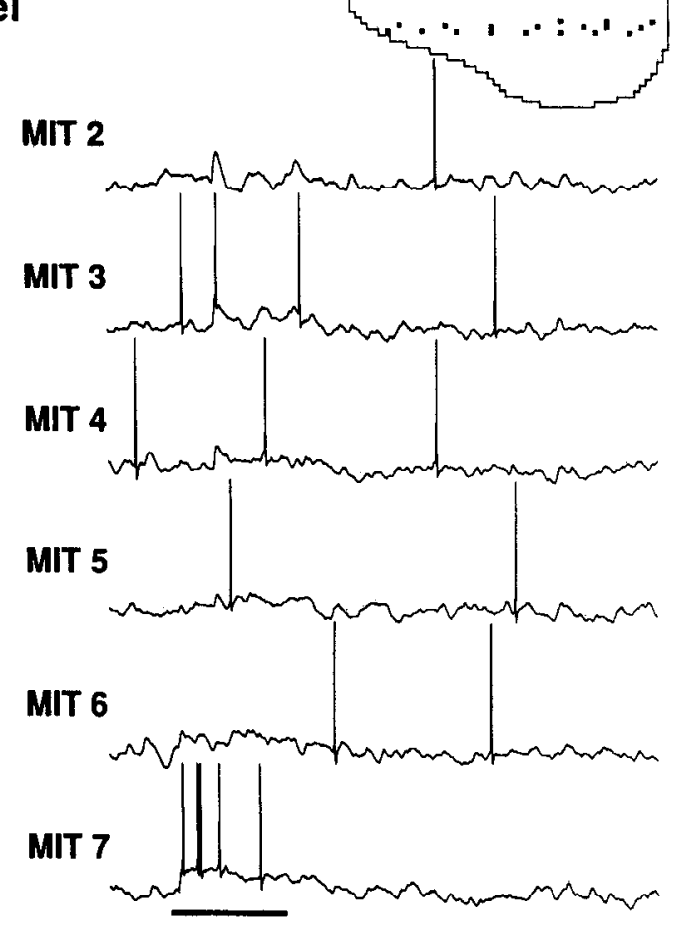

\section{b. Salamander}

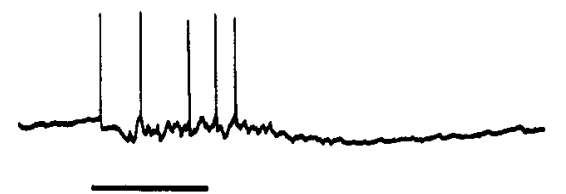

\section{B High Intensity Odor}

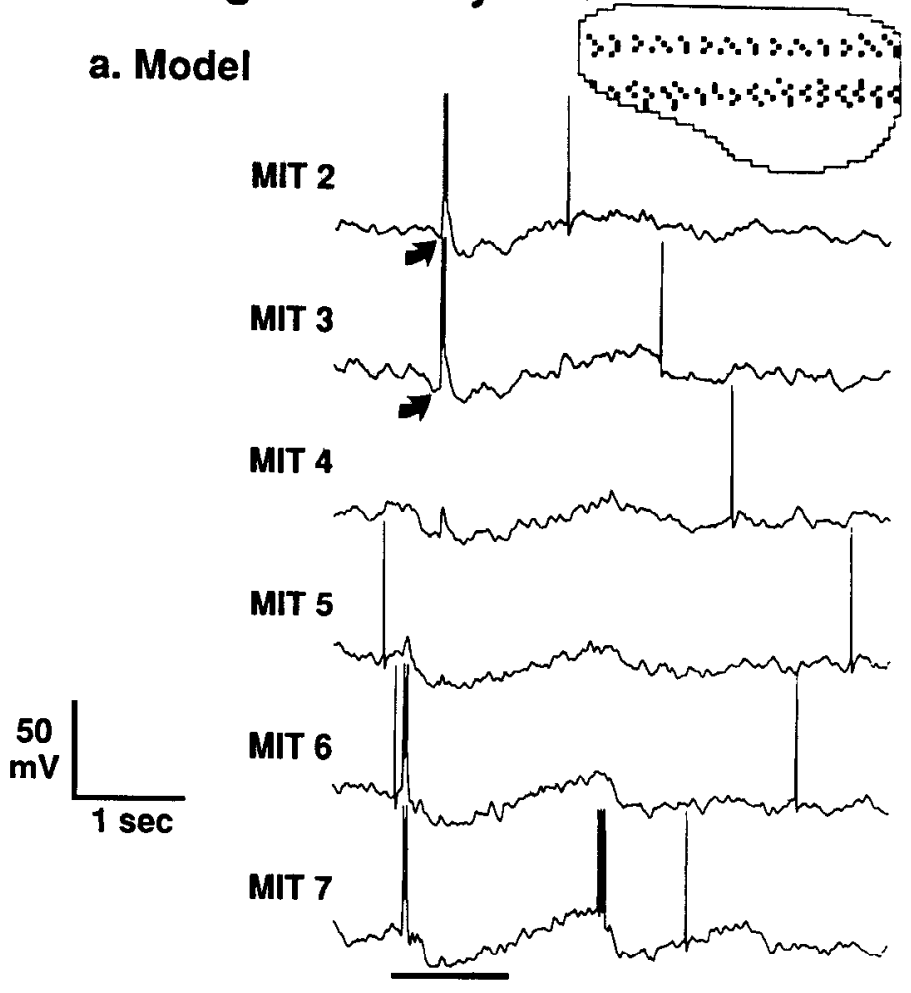

b. Salamander

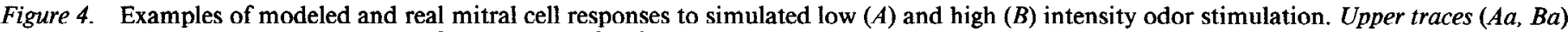

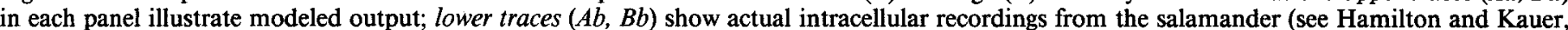

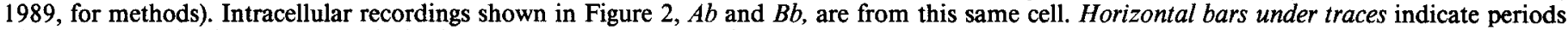

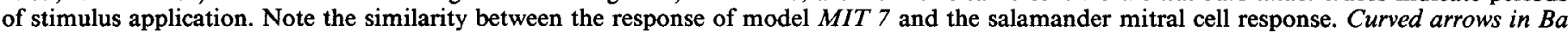

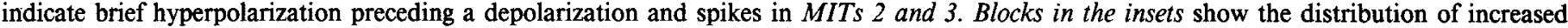

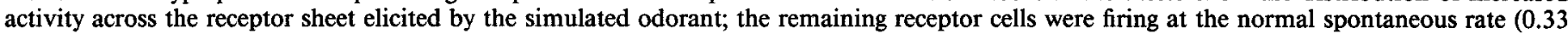

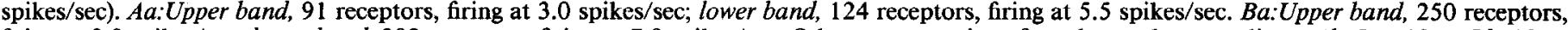

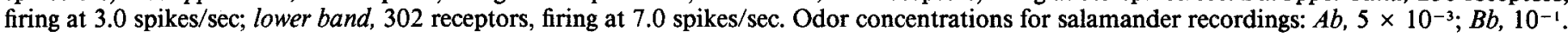

6 fired bursts of two action potentials and were subsequently hyperpolarized ( $E_{2}$ response-brief burst and suppression). MIT 7 showed a spike burst and hyperpolarization, followed by a second depolarization and burst of spikes, similar to $E_{3}$ responses (excitation, suppression, excitation) first described in extracellular recordings (Kauer, 1974). MITs 4 and 5 were hyperpolarized during the early part of the stimulus, with some preceding depolarization but no spikes, similar to $S_{1}$ responses (uniform suppression). MITs 2 and 3 showed a brief hyperpolarization that preceded the short depolarization and spikes (curved arrows in Fig. $4 \mathrm{Ba}$ ), similar to potentials seen in salamander intracellular mitral recordings after moderate concentration odor stimulation (Hamilton and Kauer, 1989). Figure $4 B b$ shows the same salamander cell as Figure $4 A b$, responding to a higher concentration of cineole $\left(10^{-1}\right.$ saturated vapor). The membrane potential changes and spiking pattern of this $E_{3}$-like response are again qualitatively similar to those of MIT 7.

The similarity of the model's output to salamander olfactory bulb recordings suggests that the general framework of the model is satisfactory for further investigation of the precise influences each component and connection has on the response. This work is in progress and is beyond the scope of this initial report, which focuses on a description of the model itself. We have, however, explored the effects of manipulating one of the major components of the model, namely GLM/PGL and MIT/GRL lateral interactions, in order to examine the extent to which these critically determine the output. With "normal" lateral interactions (line A in Table 1), the output of the model remained stable and gave rise to the mitral cell outputs shown in Figures 2, 4, and $5 A$. The responses are similar to recordings from salamander mitral cells as described above. Reducing the extent of the lateral interactions (i.e., shortening MIT dendritic length) led to a progressive increase in MIT spike activity and bursting behavior. Reduction to one-fifth that of the normal condition (line B, Table 1) caused the MIT membrane potential to oscillate continuously (Fig. $5 B$ ), and complete removal of lateral interactions (line $\mathrm{C}$ in Table 1) produced more pronounced oscillations in MIT membrane potential with longer 


\section{A Normal Lateral Connections}

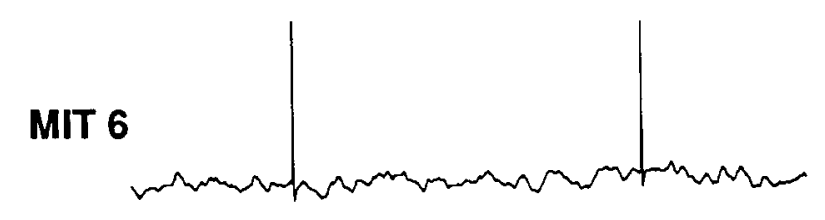

\section{Reduced Lateral Connections}

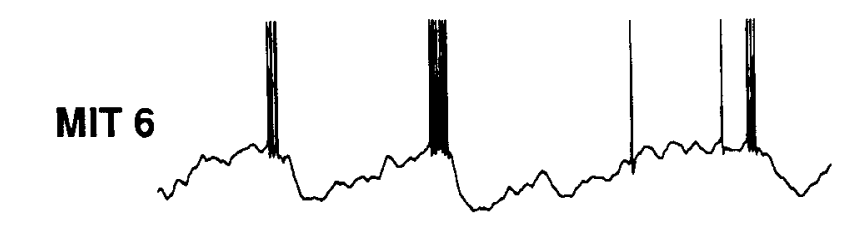

C No Lateral Connections

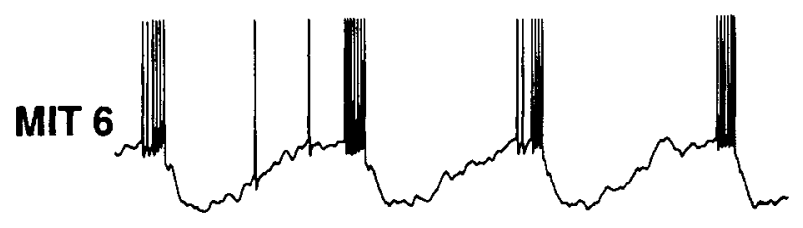

Do Inhibition
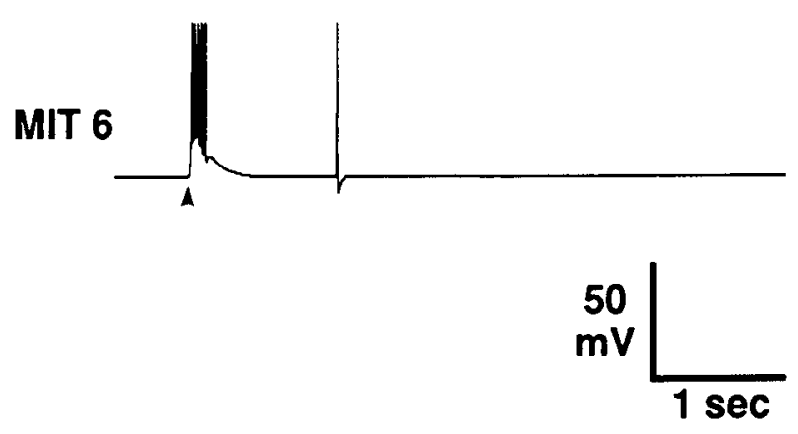

Figure 5. Examples of model mitral cell activity following manipulations of lateral inhibitory interactions. $A$, Activity with normal connections, as used in Figures $2-4$ (line A in Table 1). Membrane potential is stable, and two spontaneous spikes occurred. $B$, Activity with lateral PGL and GRL connections reduced to one-fifth of that in $A$ (line B in Table 1). Oscillating periods of membrane depolarization, action potential bursts, and hyperpolarization are evident. $C$, Activity with lateral connections removed entirely (line $\mathrm{C}$ in Table 1). The cell exhibited more pronounced membrane potential oscillations with longer bursts of impulses. $D$, Effect of completely removing inhibitory inputs from PGLs and GRLs. Here, spontancous receptor activity was climinated to simulate an in vitro recording (see Nowycky et al., 1981). A single orthodromic electrical stimulation (arrowhead) elicited a large, $400 \mathrm{msec}$ depolarization and burst of five action potentials.

spike burst durations (Fig. 5C). Orthodromic electrical stimulation reset the oscillation, while odor stimulation reset the oscillations and decreased the period of the spike bursts during the odor pulse (data not shown). Oscillations in membrane potential such as these are not normally observed in recordings from salamander mitral cells (see Discussion).
In an additional test of one of the model parameters, the inhibitory inputs to the MITs were removed as shown in Figure $5 D$. To simulate in vitro conditions used by Nowycky et al. (1981), the receptors were prevented from firing spontaneously in this test. As expected, no hyperpolarizing potentials were seen in MITs after electrical stimulation (using the same stimulus conditions as in Fig. 2A). MITs 4-7 (MIT 6 is illustrated) all exhibited depolarizations lasting approximately $400 \mathrm{msec}$, eliciting four or five spikes in each cell with latencies of 24-25 msec.

\section{Discussion}

Although we have simplified a number of bulb circuit properties, the model is the first we know of that reliably generates membrane potential and spike response patterns having great similarity to intracellular and extracellular recordings from mitral cells in vivo. Simulated mitral cell responses to relatively simple electrical stimulation (Fig. 2) and to temporally and spatially complex odorant stimulation (Fig. 4) have been generated. The similarities of the modeled output to salamander recordings suggest that the modcl incorporates some of the critical features of the interactive events in the bulbar circuitry, since manipulation of two parameters generated outputs that were unrealistic for this animal. Since the specific forms of the mitral responses were not explicitly programmed into the model, they represent response properties that have emerged from the interactions among the large numbers of elements represented in the network. We can also infer that the cellular properties and interactions that have been included in the model, although greatly simplified, are sufficient for the network to reproduce a number of those complexities of single mitral responses actually observed in the salamander.

In addition to the similarities between the model MIT outputs and salamander mitral recordings, there are two other emergent aspects of the model's odor response that may be relevant for understanding olfactory bulb function. First, when viewed across the mitral cell array, the different patterns of spike output from individual mitral cells form a spatial-temporal pattern of activity that changes with odor stimulus intensity (Fig. 4). The activity pattern across all the mitral cells also changes with different spatial patterns of receptor input (i.e., stimulation with a different "odor"). These spatial-temporal patterns of mitral activity may be important for odor information coding (Meredith, 1986b; Schild, 1986, 1988; Haberly and Bower, 1989; Li and Hopfield, 1989; Kauer, 1991). Second, the complex transition from $E_{1}$ to $E_{3}$ response types in MIT 7 with change in stimulus intensity (Fig. $4 A a, B a$ ) is similar to changes in responses of salamander mitral cells with increased odor concentration (Fig. $4 A b, B b$ ). A response profile in which a mitral cell shows sustained firing over a limited concentration range above and below which it is suppressed has been termed "concentration tuning" in salamander mitral cells (Kauer, 1974), and the model faithfully replicates this response feature. Additionally, the change in MIT 5 from no response at low concentration to a suppression at high concentration has also been observed in salamander recordings (Kauer, 1974; Hamilton and Kauer, 1989). The model thus reproduces the kinds of transitions between responses at low and high odor stimulus intensities that are seen in salamander recordings, suggesting that these transitions may also be emergent properties of network interactions.

Although single-unit recordings from interneurons in the salamander have not been published, the PGL and GRL responses shown in Figure 3 compare well with recordings from periglo- 
merular and granule cells in other species and may be viewed as another emergent property of the model. As in the model, mammalian periglomerular cells tend to be noisy and fire bursts of action potentials. following single olfactory nerve shocks (Getchell and Shepherd, 1975; Wellis and Scott, 1990). Also similar to the model, rat periglomerular cells respond to odor stimulation with long-duration bursts of action potentials (Wellis and Scott, 1990). The convergence of many receptor cells onto the GLMs and PGLs and the high spike activity in the PGLs is also consistent with the band of high 2-deoxyglucose uptake in the glomerular layer under resting conditions (Sharp et al., 1975).

Granule cells in the rat and turtle respond to electrical stimulation of the olfactory nerve with small depolarizations and brief bursts of action potentials (Jahr and Nicoll, 1982; Wellis and Scott, 1990). With odor stimulation, granule cells in the rat depolarize and fire either short- or long-duration bursts of action potentials (Wellis and Scott, 1990). The similarities between the model PGL and GRL responses and those from actual interneuron recordings provide additional validation of the present approach. As for the mitral cells, specific interneuron responses were not programmed into the model, yet realistic responses emerged. Given reasonable cellular parameters and connections (Fig. 1 $A$, Table 1), these specific PGL and GRL responses were produced by interactions within the model network.

Many anatomical and physiological details of the olfactory bulb have not been included in the present model. For example, while the general form of mitral and tufted cell collateral connections with periglomerular, granule, and short axon cells have been described (Herrick, 1924; Mori, 1987; Halasz, 1990), specific details of the microcircuits are still lacking. Thus, the model is not only important for organizing and formalizing data already available; it also highlights particular physiological and anatomical information that is missing. We will continue to develop the model and test its accuracy as additional data become available.

The present model was designed to adhere as closely as possible to known anatomical and physiological properties of individual bulbar cells in a single experimental species. Thus, its output, in the form of changes in membrane potential in a large number of cells, can now be the basis for analyzing how ensemble events might arise from interactions among these many individual cellular elements. As an explicit simulation of intracellular responses, this model differs from others that have examined the more global properties of oscillatory behavior and phase relationships in EEG recordings (Freeman, 1987; Li and Hopfield, 1989), properties of electrically evoked field potentials (Rall and Shepherd, 1968), regional distributions of excitation and inhibition (Meredith, 1986b), and behavioral responses to odor stimuli (Gelperin et al., 1989). This model also differs from a recent description of the olfactory pathway from the standpoint of information theory (Schild, 1986, 1988). Although cach model differs in approach, the various aspects of bulbar behavior described by these other models may also potentially be investigated with our model. For example, global EEG events are presumed to arise from synchronous activity in many individual cells. Since our model calculates single cell activity, simulated EEGs may be derived by appropriately summing the activity of many cells. The model output could then be examined in the context of the Freeman (1987) and Li and Hopfield (1989) models mentioned above.

We have tested the effects of manipulating a basic parameter of the model (degree of lateral interaction) as a first step in exploring in detail the features that critically determine its output. When lateral interactions were reduced or eliminated, output mitral cells showed periods of oscillation, consisting of bursts of spikes and hyperpolarization (Fig. $5 B, C$ ), even in the absence of stimulation. These observations suggest that the overlapping, divergent/convergent nature of the connections (Kauer, 1991) may be an essential component for stabilizing the circuit, as well as for producing the patterns of mitral cell response observed during electrical and odor stimulation. It also implies that lateral inhibition, not only self-inhibition, is important for generating the observed responses (Woolf et al., 1991a,b). Although not generally observed in the tiger salamander, oscillatory behavior is consistently seen in EEG recordings from the mammalian olfactory bulb (Di Prisco and Freeman, 1985; Freeman, 1987). It may be that differences in dendritic geometry between species may contribute to the observed electrophysiological differences.

These observations suggest that a reduction in lateral interactions may also be a factor involved in aberrant, synchronous oscillatory behavior such as those in epileptic foci where, for example, reduced arborization and dendritic overlap might contribute to instability. Although hippocampal microcircuitry differs from that of the olfactory bulb, reductions in dendritic arborization in epileptic foci in the hippocampus have, in fact, been observed (Babb and Brown, 1986; Paul and Scheibel, 1986). Thus, the present model can direct attention to factors that might influence the behavior of other systems that are not immediately obvious from single-unit recordings.

Although it is not possible at present to reduce anatomical lateral interactions experimentally, this might be effectively accomplished by manipulating other physiological parameters using pharmacological approaches. Thus, the model permits testing hypotheses about both single cell and global olfactory bulb functions, which then can be validated in single unit and ensemble (e.g., voltage-sensitive dye) recording experiments. For example, in another test of how specific components of the model contribute to the output, we have removed all the feedforward and feedback inhibitory connections from periglomerular and granule cells. Under these conditions, orthodromic electrical stimulation results in long-lasting mitral depolarization with sustained spiking, but no following hyperpolarization (Fig. $5 D$ ). This finding is similar to responses observed in turtle mitral cells after application of the $\mathrm{GABA}_{\mathrm{A}}$ antagonist bicuculline (Nowycky et al., 1981). Such interactive comparisons between simulated and real physiology may help us to understand better the complex, parallel distributed properties that appear to encode odor information in the olfactory pathway. This approach might also help to characterize, in formal terms, sets of general rules that underlie information processing mechanisms in real neuronal networks.

\section{References}

Babb TL, Brown WJ (1986) Neuronal, dendritic, and vascular profiles of human temporal lobe epilepsy correlated with cellular physiology in vivo. Adv Neurol 44:949-966.

Breipohl W, Moulton D, Ummels M, Matulionis DH (1982) Spatial pattern of sensory cell terminals in the olfactory sac of the tiger salamander. I. A scanning electron microscope study. J Anat 134:757769.

Di Prisco GV, Freeman WJ (1985) Odor-related bulbar EEG spatial pattern analysis during appetitive conditioning in rabbits. Behav Neurosci 99:964-978. 
Firestein S, Werblin FS (1989) Odor-induced membrane currents in vertebrate olfactory receptor neurons. Science 244:79-82.

Freeman WJ (1987) Simulation of chaotic EEG patterns with a dynamic model of the olfactory system. Biol Cybern 56:139-150.

Gelperin A, Tank DW, Tesauro G (1989) Olfactory processing and associative memory: cellular and modeling studies. In: Neural models of plasticity: experimental and theoretical approaches (Byrne $\mathrm{JH}, \mathrm{Ber}-$ ry WO, eds), pp 133-159. New York: Academic.

Getchell TV, Shepherd GM (1975) Short axon cells in the olfactory bulb: dendrodendritic synaptic interactions. J Physiol (Lond) 251: 523-548.

Getchell TV, Shepherd GM (1978a) Responses of olfactory receptor cclls to step pulses of odour at different concentrations in the salamander. J Physiol (Lond) 282:521-540.

Getchell TV, Shepherd GM (1978b) Adaptive properties of olfactory receptors analyzed with odour pulses of varying durations. J Physiol (Lond) 282:541-560.

Graziadei PPC, Graziadei GAM (1976) Olfactory epithelium of Necturus maculosus and Ambystoma tigrinum. J Neurocytol 5:11-32.

Haberly LB, Bower JM (1989) Olfactory cortex: model circuit for study of associative memory. Trends Neurosci 12:258-264.

Halasz N (1990) The vertebrate olfactory system. Budapest: Akademiai Kiado.

Hamilton KA, Kauer JS (1988) Responses of mitral/tufted cells to orthodromic and antidromic electrical stimulation in the olfactory bulb of the tiger salamander. J Neurophysiol 59:1736-1755.

Hamilton KA, Kauer JS (1989) Patterns of intracellular potentials in salamander mitral/tufted cells in response to odor stimulation. J Neurophysiol 62:609-625.

Harrison TA, Scott JW (1986) Olfactory bulb responses to odor stimulation: analysis of response pattern and intensity relationships. $J$ Neurophysiol 56:1571-1589.

Herrick CJ (1924) The amphibian forebrain: II. The olfactory bulb of Amblystoma. J Comp Neurol 37:373-396.

Hodgkin AL, Huxley AF (1952) A quantitative description of membrane current and its application to conduction and excitation in nerve. J Physiol (Lond) 117:500-544.

Jahr CE, Nicoll RA (1982) An intracellular analysis of dendrodendritic inhibition in the turtle in vitro olfactory bulb. J Physiol (Lond) 326: 213-234.

Kauer JS (1974) Response patterns of amphibian olfactory bulb neurones to odour stimulation. J Physiol (Lond) 243:695-716.

Kauer JS (1980) Some spatial characteristics of central information processing in the vertebrate olfactory pathway. In: Olfaction and taste VII (van der Starre H, ed), pp 227-236. London: IRL.

Kauer JS (1988) Real-time imaging of evoked activity in local circuits of the salamander olfactory bulb. Nature 331:166-168.

Kauer JS (1991) Contributions of topography and parallel processing to odor coding in the vertebrate olfactory pathway. Trends Neurosci 14:79-85.

Kauer JS, Moulton DG (1974) Responses of olfactory bulb neurones to odour stimulation of small nasal areas in the salamander. J Physiol (Lond) 243:717-737.

Kauer JS, Shepherd GM (1977) Analysis of the onset phase of olfactory bulb unit responses to odor pulses in the salamander. J Physiol (Lond) 272:495-516.

Kauer JS, Senseman DM, Cohen LB (1987) Odor-elicited activity monitored simultaneously from 124 regions of the salamander olfactory bulb using a voltage-sensitive dye. Brain Res 418:255-261.

Kent PF, Mozell MM (1988) The recording of odorant-induced mucosal activity patterns with a voltage-sensitive dye. Chem Senses 13: 704.

Lancet D, Greer CA, Kauer JS, Shepherd GM (1982) Mapping of odor-related neuronal activity in the olfactory bulb by high-resolution 2-deoxyglucose autoradiography. Proc Natl Acad Sci USA 79:670674.

Li Z, Hopfield JJ (1989) Modeling the olfactory bulb and its neural oscillatory processings. Biol Cybern 61:379-392.

Mackay-Sim A, Kubie JL (1981) The salamander nose: a model system for the study of spatial coding of odor quality. Chem Senses 6:249265.

Mackay-Sim A, Shamam P, Moulton DG (1982) Topographic coding of olfactory quality: odorant-specific patterns of epithelial responsivity in the salamander. J Neurophysiol 48:584-596.
Mair RG (1982) Response properties of rat olfactory bulb neurones. J Phvsiol (Lond) 326:341-359.

Martinez DP, Freeman WJ (1984) Periglomerular cell action on mitral cells in olfactory bulb shown by current source density analysis. Brain Res 308:223-233.

Mason JR, Stevens DA, Rabin MD (1980) Instrumentally conditioned avoidance by tiger salamanders (Ambystoma tigrinum) to reagent grade odorants. Chem Senses 5:99-105.

Meredith M (1986a) Pattern response to odor in mammalian olfactory bulb: the influence of intensity. J Neurophysiol 56:572-597.

Meredith M (1986b) Temporal and spatial patterns of response to odor in the hamster olfactory bulb: single unit recordings and computer simulation. Chem Senses 11:638.

Mori K (1987) Membrane and synaptic properties of identified neurons in the olfactory bulb. Prog Neurobiol 29:275-320.

Mori K, Nowycky MC, Shepherd GM (1981) Electrophysiological analysis of mitral cells in the isolated turtle olfactory bulb. J Physiol (Lond) 314:281-294

Mori K, Nowycky MC, Shepherd GM (1984) Synaptic excitatory and inhibitory interactions at distal dendritic sites on mitral cells in the isolated turtle olfactory bulb. J Neurosci 4:2291-2296.

Nowycky MC, Mori K, Shepherd GM (1981) GABAergic mechanisms of dendrodendritic synapses in isolated turtle olfactory bulb. J Neurophysiol 46:639-648.

Orbach HS, Cohen LB (1983) Optical monitoring of activity from many areas of the in vitro and in vivo salamander olfactory bulb: a new method for studying functional organization in the vertebrate central nervous system. J Neurosci 3:2251-2262.

Paul LA, Scheibel AB (1986) Structural substrates of epilepsy. Adv Neurol 44:775-786.

Rall W (1964) Theoretical significance of dendritic trees for neuronal input-output relations. In: Neural theory and modelling (Reiss RF, ed), pp 73-97. Palo Alto, CA: Stanford UP.

Rall W, Shepherd GM (1968) Theoretical reconstruction of field potentials and dendrodendritic synaptic interactions in the olfactory bulb. J Neurophysiol 31:884-915.

Schild D (1986) Systems analysis of the goldfish olfactory bulb: spatiotemporal transfer properties of the mitral-granule cell complex. Biol Cybern 54:9-19.

Schild D (1988) Principles of odor coding and a neural network for odor discrimination. Biophys J 54:1011.

Scott JW (1981) Electrophysiological identification of mitral and tufted cells and distributions of their axons in olfactory system of the rat. J Neurophysiol 46:918-931.

Senseman DM, Vasquez S, Nash PL (1990) Animated pseudocolor activity maps (PAM'S): scientific visualization of brain electrical activity. In: NATO ASI Series H, Vol 39, Chemosensory information processing (Schild D, ed), pp 329-347. Berlin: Springer.

Sharp FR, Kauer JS, Shepherd GM (1975) Local sites of activityrelated glucose metabolism in rat olfactory bulb during olfactory stimulation. Brain Res 98:596-600.

Shepherd GM (1972) Synaptic organization of the mammalian olfactory bulb. Physiol Rev 52:864-917.

Trotier D, MacLeod P (1983) Intracellular recordings from salamander olfactory receptor cells. Brain Res 268:225-237.

Wellis DP, Kauer JS (1991) Whole cell patch and optical recordings of synaptic responses in salamander olfactory bulb. Soc Neurosci Abstr 17:636.

Wellis DP, Scott JW (1990) Intracellular responses of identified rat olfactory bulb interneurons to electrical and odor stimulation. J Neurophysiol 64:932-947.

Wellis DP, Scott JW, Harrison TA (1989) Discrimination among odorants by single neurons of the rat olfactory bulb. J Neurophysiol 61: 1161-1177.

Wilson MA, Bower JM (1989) The simulation of large-scale neural networks. In: Methods in neuronal modeling: from synapses to networks (Koch C, Segev I, eds), pp 291-333. Cambridge, MA: MIT Press

Woolf TB, Shepherd GM, Greer CA (1991a) Serial reconstructions of granule cell spines in the mammalian olfactory bulb. Synapse 7:181192.

Woolf TB, Shepherd GM, Greer CA (1991b) Local information processing in dendritic trees: subsets of spines in granule cells of the mammalian olfactory bulb. J Neurosci 11:1837-1854. 